\title{
Gender differences in the age-cohort distribution of psychological distress in Canadian adults: findings from a national longitudinal survey
}

\author{
Aline Drapeau ${ }^{1,2,3^{*}}$, Alain Marchand ${ }^{4,5}$ and Charlotte Forest ${ }^{1,6}$
}

\begin{abstract}
Background: Psychological distress is frequently used as an indicator of the mental health of a population. Overall, the mean level of distress is higher in women than in men and tends to decrease in both genders during adulthood. This pattern is primarily attributable to the differential exposure of women and men to specific risk factors over their lifetimes. However, the age distribution for distress may be confounded by a cohort effect. This study aimed to compare the age and birth cohort distribution of psychological distress by gender.

Methods: This study was based on data from the National Population Health Survey, a longitudinal population survey conducted in Canada from 1994-1995 to 2010-2011. Growth curve analyses were performed separately in women $(n=9062)$ and in men $(n=7877)$ to examine the distribution of psychological distress by age group and birth cohort in Canadians aged 18 years and older.

Results: The mean level of psychological distress is higher in women than in men in all age groups and all birth cohorts, and in the 18-29 age group than in older adults. Minor gender differences are found in the distribution of distress when age and birth cohort are examined jointly. In women, the mean level of distress decreases steadily beginning at age 18, reaches its lowest point in the 60-69 age group and rises thereafter without ever reaching the level observed in young adults. In men, it remains stable in the twenties and then follows a pattern similar to that observed in women. This age pattern is more apparent in more recent than in earlier cohorts and is related to variations in employment status, marital status and education during adulthood.

Conclusions: Young adults and, to a lesser degree, seniors are at higher risk for psychological distress than other adults. To better understand the epidemiology of psychological distress, future research should focus on the risk factors that are more prevalent in these age groups. A starting point would be to evaluate how employment status, marital status and educational level change during adulthood and have changed over time in women and in men.
\end{abstract}

Keywords: Psychological distress, Age, Cohort, Adults, Gender, Growth curve analysis, Longitudinal survey, Canada

\section{Background}

Psychological distress is a state of emotional suffering characterized by moderate to severe depressive and anxiety symptoms (Drapeau et al. 2011; Mirowsky and Ross 2002). It is a marker of the severity of symptoms for major depression and anxiety disorders and a diagnostic criterion for post-traumatic stress disorder (Knapp et al. 2007). Because of its association with certain psychiatric

\footnotetext{
* Correspondence: aline.drapeau@umontreal.ca

${ }^{1}$ Centre de recherche - Institut universitaire en santé mentale de Montréal, 7331 rue Hochelaga, H1N 3 X6 Montreal, Canada

2Département de psychiatrie, Université de Montréal, Montréal, Canada Full list of author information is available at the end of the article
}

disorders (Knapp et al. 2007; Organisation mondiale de la santé 2006; Phillips 2009) and with the use of mental health services (Gudmundsdottir and Vilhjalmsson 2010; Koopmans et al. 2005; Lin et al. 2012; Svensson et al. 2009), psychological distress is used as an indicator of population mental health by public health institutions worldwide (Delorme et al. 2005; Herman et al. 2005). In adults, the annual prevalence of psychological distress ranges from 10\% in Australia (Chittleborough et al. 2011) to $21 \%$ in Canada (Caron and Liu 2011) and 27\% in Japan (Sakurai et al. 2010), Great Britain (Benzeval and Judge 2001) and Belgium (Levecque et al. 2009). The prevalence 
and mean level of distress tend to decrease over the life course beginning in early adulthood (Caron and Liu 2011; Gispert et al. 2003; Jorm et al. 2005; Langlois and Garner 2013; Phongsavan et al. 2006; Walters et al. 2002).

Though the negative association between age and psychological distress has been repeatedly observed, the shape of the curve describing the age distribution of distress remains ambiguous. For instance, Schieman et al. (2001) and Turcotte and Schellenberg (2007) have shown that the mean levels of distress were higher in young Americans and Canadians than in older adults. Levels then decreased with age, reaching a minimum between ages 60 and 69 (Schieman et al. 2001) or 65 and 74 (Turcotte and Schellenberg 2007) before increasing in those older than 74. A U-shaped distribution was also noted by Sacker and Wiggins (2002) despite the fact that the British sample under study was much younger, ranging from 23 to 42 years of age. In addition, Jorm et al. (2005) have provided some evidence that the age distribution of psychological distress may vary by gender. This study, based on Australians in three specific age groups (20-24, 40-44 and 60-64), found that the mean level of distress among men was similar in the first two age groups and lower in the oldest group, whereas it diminished at a constant rate between ages 20 and 64 among women.

The age distribution for depression and anxiety symptoms could shed some light on the age distribution for psychological distress, given the strong relationship between the former and the latter. Unfortunately, data on the distribution of anxiety symptoms by age are lacking for the general population. Findings regarding the age distribution for depression symptoms, moreover, are conflicting. Most studies support a U-shaped distribution for depression symptoms, but the age cohort at which symptoms reach their lowest levels remains unclear. The mean level of depressive symptoms tends to be higher among young adults, then diminishes until the forties (Mirowsky and Kim 2007), mid-fifties (Kessler et al. 1992) or sixties (Schieman et al. 2001) before again increasing among those aged 70 and older. Roberts et al. (1991) compared the prevalence of depression by age in 1965, 1974 and 1983 and found no statistically significant differences between young and middle-aged adults. However, that study did find higher prevalences for those aged 62 years and older (in 1965), 70 years and older (in 1974) and 80 years and older (in 1983). According to Roberts et al. (1991), the variation in peak depression prevalence among seniors between 1965 and 1983 could indicate that the age distribution observed in other studies is biased by a cohort effect.

Variations in psychological distress and other health problems during adulthood have been primarily attributed to differential lifetime exposures to specific risk factors (Jorm et al. 2005; Schieman et al. 2001). Some risk factors commonly associated with psychological distress, such as low educational level (Brault et al. 2011; Caron and Liu 2011; Jorm et al. 2005; Schieman et al. 2001), lack of a spouse (Brault et al. 2011; Caron and Liu 2011; Jorm et al. 2005; Kasen et al. 2003; Schieman et al. 2001; Yang 2007) and non-employment (Brault et al. 2011; Chiao et al. 2009; Jorm et al. 2005; Schieman et al. 2001; Walters et al. 2002), follow a U-shaped distribution that matches the age distribution for psychological distress during adulthood found in some studies. For example, in Canada the percentage of the population having completed high school or less is higher for those aged 15-24 (34\%) and 65 and older (38\%) than for those aged 25-54 (10\%) or 55-64 (16\%) (Statistique Canada 2012). The youngest age group includes teenagers who, as a rule, have not yet finished high school. Those aged 65 and older grew up at a time when high school diplomas were much less common than they are today. Similarly, having no spouse (i.e.,single, divorced, separated or widowed) is most frequent among those aged 20-24 (84\%), reaches minimum levels between ages 3569 (29\%) and gradually increases, primarily because of the death of a spouse, to $59 \%$ between ages 75 and 79 and more than $80 \%$ after age 90 (Statistique Canada 2013). Finally, non-employment is relatively high among those aged 15-24 (45\%), drops to $19 \%$ between ages 25 and 54 and then increases to $41 \%$ among those aged 55-64 and to 89\% among those aged 65 years and older (Statistique Canada 2011). Nonemployment among younger people may be high in part because of college or university enrolment. Older adults generally start retiring in their sixties.

An alternative explanation for the distribution of psychological distress by age is the cohort effect (Brault et al. 2011; Chiao et al. 2009; Kasen et al. 2003; Jorm 2000; Lewinsohn et al. 1993; Mirowsky and Kim 2007; Roberts et al. 1991; Sacker and Wiggins 2002; Yang 2007). The cohort effect results from generational exposure to unique combinations of social and cultural factors, which differentiate each birth cohort from previous and subsequent generations (Susser et al. 2006). To our knowledge, only one study (Sacker and Wiggins 2002) sought to disentangle the effects that age and cohort had on the distribution of psychological distress in the general population. The study analysed the data pooled from two longitudinal surveys conducted in the United Kingdom: the National Child Development Study (NCDS) and the 1970 British Birth Cohort Study (BCS70). The NCDS targeted people born in one week in $1958(n=14$ 663), whereas the BCS70 focused on those born in one week in 1970 ( $n=12$ 597). The study by Sacker and Wiggins (2002) was restricted to data collected when NCDS respondents were 23, 33 and 42 years of age and BCS70 respondents were 26 and 30 years of age. Sacker and Wiggins (2002) observed significant age and cohort effects. The rate of highly distressed individuals followed a U-shaped age 
distribution; the youngest cohort (born in 1970) had a higher rate of distress than the oldest cohort (born in 1958). The interaction between age and cohort effects was not statistically significant.

The age and cohort effects and their interaction have also been investigated for depression and depressive symptoms (Brault et al. 2011; Chiao et al. 2009; Kasen et al. 2003; Lewinsohn et al. 1993; Mirowsky and Kim 2007; Roberts et al. 1991; Yang 2007). But only the study conducted by Brault et al. (2011) covers a broad age range and includes several waves of data collection. It was based on data from the Panel Study of Belgian Households (PSBH), a longitudinal population survey with collected data each year between 1992 and 2002 (Brault et al. 2011). The analyses were restricted to respondents between 25 and 74 years of age at baseline. Five cohorts were defined based on birth year (19181927, 1928-1937, 1938-1947, 1948-1957 and 19581967); cohort membership was treated as a categorical variable and analysed with four dummy variables. Statistically significant effects were found for age, cohort and interaction between age and cohort. Unlike the findings in studies conducted by Kessler et al. (1992), Mirowsky and Kim (2007) and Schieman et al. (2001), Brault et al. (2011) found that the mean level of depression symptoms increased slightly with age. They also noted statistically significant effects for birth cohort and for age-cohort interaction. These effects showed that the mean level of depression symptoms was higher in more recent cohorts than in earlier cohorts and that the tendency of symptoms to increase with age was more pronounced in more recent cohorts. Controlling for gender, marital status, education, income and employment status did not alter the cohort effect or the interaction between age and cohort. Other studies that investigated the effects of age and cohort on the distribution of depression symptoms were based on selective samples, which limited the generalisability of their findings. The study by Yang (2007) was limited to seniors (aged 65 to 95); Chiao et al. (2009) restricted their study to those aged 60 to 69; and Kasen et al. (2003) studied only mothers from 35 to 55 years of age.

Taken together, findings from the studies that examined the effects of age and cohort on the distribution of psychological distress and depressive symptoms suggest that gender differences, cohort effect and the interaction of age and cohort effects should be taken into account if the distribution of psychological distress during adulthood is to be fully understood. The main objective of our study was to examine the effects of age and birth cohorts on the distribution of psychological distress in Canadian adults. More specifically, it aimed to compare the patterns of the age and birth cohort distributions for psychological distress in women and men and to verify to what extent educational level, marital status and employment status account for this distribution.

\section{Methods \\ Study population}

This study is based on data from the National Population Health Study (NPHS). The NPHS is a longitudinal population survey conducted by Statistics Canada every two years from 1994-1995 to 2010-2011 (9 waves). It assessed the health status, lifestyle and health care practices of Canadians. The target population of the NPHS comprised Canadians aged 12 years and older and living in private households. At baseline (1994-1995), respondents were selected using a multi-level stratified sampling strategy to identify 20095 households from which one person was selected at random; the response rate was $86 \%$. Additional information regarding the design of the NPHS can be found in Catlin and Will (1992) and Tambay and Catlin (1995).

In this study, analyses were restricted to adult respondents. Between 1994-1995 and 2010-2011, 16939 respondents (women $\mathrm{n}=9062$; men $\mathrm{n}=7877$ ) 18 years old and older took part in the NPHS. Among these, 1405 women and 1428 men became eligible for this study after baseline since they reached 18 years old between waves 2 and 9 of the NPHS. The 16939 respondents generated 127322 observations (women $n=69020$; men $n=58302$ ). Over the course of the survey, one third of adult respondents (women $32.0 \%$; men $35.8 \%$ ) were permanently or temporarily lost to follow-up (i.e., they missed one wave but participated in the next wave). Those lost to follow-up tended to have a higher mean level of psychological distress in the wave preceding their withdrawal than those who remained part of the survey.

\section{Dependent variable}

Psychological distress was assessed with the K6, a scale developed by Kessler and his colleagues and used in several population surveys (Kessler et al. 2002; Kessler et al. 2003; Furukawa et al. 2003; Baillie 2005). The $K 6$ is a unidimensional scale comprising 6 items asking respondents how often during the preceding 30 days they felt: so sad that nothing could cheer them up; nervous; restless or fidgety; hopeless; worthless; that everything was an effort. Each item is scaled from 0 (none of the time) to 4 (all of the time). The total score of psychological distress is computed by summing the six items scores and ranges from 0 to 24 . Items with missing values were replaced with the mean of valid items among respondents with valid answers to four or five items of the K6 before computing the total distress score (rounded to the nearest unit). Respondents with valid answers to three items or fewer were coded as missing values for 
the distress score. In this study, the reliability of the K6 ranged from $\alpha_{\text {Cronbach }}=.72$ to $\alpha_{\text {Cronbach }}=.84$ over the 9 waves of the NPHS. The measurement and structural invariance of the $\mathrm{K} 6$ across gender was demonstrated in a previous paper (Drapeau et al. 2010).

\section{Independent variables}

Age was analyzed as a continuous time-varying variable and was centred at 18 years of age (i.e., 18 years $=0$ ). Quadratic age and cubic age were input to model the curvilinear age distribution that has been observed for psychological distress in other studies (Langlois and Garner 2013; Sacker and Wiggins 2002; Schieman et al. 2001; Turcotte and Schellenberg 2007). Birth cohorts were divided into 10-year periods except for the most recent (1980 to 1995) and the earliest (1893 to 1919) cohorts, both of which span more than a decade (15 and 26 years, respectively) in order to ensure a sufficient number of respondents in each cohort. The successive cohorts were coded 0 (1980 to 1995) to 7 (1893 to 1919). Three time-varying covariates were taken into account: educational level (high school or less $=2$; post high school education $=1$; university diploma $=0$ ), marital status (without spouse i.e., single, divorced, separated or widowed $=1$; with legal or common-law spouse $=0$ ), and employment status (not employed $=1$; full-time or part-time workers $=0$ ). Not employed include volunteer workers, retirees and individuals who are not in the work market for any reasons. Employed include salaried employees, self-employed workers and workers on sick leave or temporarily absent from work for family reasons.

\section{Statistical analyses}

Hierarchical growth curve analyses were conducted separately for women and men to examine the effects of age and birth cohort on the distribution of psychological distress. Growth curve analysis is a form of multilevel analysis for longitudinal data where data collected at each wave (level 2) are nested in individuals (level 1) (Rabe-Hesketh and Skrondal 2012). It is used to describe the trajectory of a phenomenon over time by simultaneously taking into account the intra- and inter-individual variation of this trajectory. The two main parameters, the intercept (i.e., initial level) and the slope (i.e., growth or decline rate), have two dimensions: a fixed dimension reflecting the mean value of the parameter and a random dimension corresponding to the individual variations around this mean. In this study, the coefficient for age estimates the intra-individual growth rate of distress during adulthood, the coefficient for cohort estimates the inter-individual variation of distress over time, and the interaction between age and cohort estimates variation in the growth rate over time. Hierarchical growth curve analyses by gender comprise five consecutive models. Model 1, the null model, includes only the intercept and serves to verify the presence of random variation in the trajectory of psychological distress. Model 2 includes the age variables (i.e., age, age ${ }^{2}$ and age $^{3}$ ) and assesses the crude effect of time on the trajectory of distress. Birth cohort is added in Model 3, and the interaction between age and birth cohort in Model 4. Model 5 includes the time-varying covariates (i.e., education, marital status and employment status) and aims to verify to what extent these covariates explain the results observed in Model 4. Growth curve analyses were carried out using the mi-xtmixed function of Stata version 13 . They were based on weighted data to control for the non response and loss to follow-up during the NPHS. These weights are estimated by Statistics Canada and, in this study, they are standardized to 1 to respect sample size. Estimated standard errors of the confidence intervals were inflated by the square root of the global survey design effect.

Before undertaking growth curve analysis, missing values were replaced by imputed values to control for a potential selection bias due to selective loss to follow-up and nonresponse. Although growth curve analysis takes into account all valid data, the estimation of parameters can be biased in cases of selective attrition and non-responses. Missing values were imputed on wide- format file using the multiple imputation method developed by Rubin (1987). Multiple imputation produces several series of completed data where the missing values of a variable are replaced by values predicted by linear, ordinal or logistic regression based on an imputation model. Statistical analyses (here, growth curve analyses) are conducted separately on each completed data set and the estimated parameters are combined using Rubin's rules (Rubin 1987). The imputation model must contain all variables used in subsequent analyses. It may also contain auxiliary variables that will not be included in the main analyses but that will improve the precision of imputed values (Collins et al. 2001; Enders 2010; Rubin 1996; Schafer and Graham 2002). In this study, the imputation model included the variables used in growth curve analyses (i.e., age; age $^{2}$; age $^{3}$; birth cohorts; interaction between age and cohort; educational level; marital status; employment status) and five auxiliary variables. These auxiliary variables were selected because they correlated with psychological distress $(r>.10)$ and because they were assessed in all nine waves of the NPHS. These variables are: subjective health perception ( 5 categories ranging from 0 "poor health" to 4 "excellent health"); number of visits to a medical practitioner (generalist or specialist) in the 12 months preceding the survey; number of depression symptoms according to the CIDI-Short Form; inability to perform daily activities in the previous two weeks (index ranging from 0 to 3 ); and number of chronic health problems indicated on a 
checklist of 19 health problems. The auxiliary variables contained few missing data (ranging from $0.01 \%$ to $6.20 \%$ ); missing values were replaced with the median value observed in men and women.

The multiple imputation of missing values for psychological distress was based on the MICE (Multiple Imputation by Chained Equation) algorithm implemented by the ICE (Iterated Chained Equation) program; MICE and ICE were both developed by Royston (Royston 2007; Royston and White 2011). The ICE program allows the user to specify the range of imputed values so that they reflect plausible minimum and maximum values (Royston and White 2011). For instance, imputed values for psychological distress ranged from 0 (minimum score) to 24 (maximum score) and were rounded to the nearest unit since K6 scores do not contain decimal values. Following Graham et al.'s recommendations (Graham et al. 2007), twenty series of completed data sets were generated. These completed data sets comprised $23.1 \%$ of imputed values for women and $27.3 \%$ for men. According to Rubin (1987), multiple imputation is problematic when the percentage of missing values exceeds 50\%. Missing values were not imputed for respondents who ceased participating in the survey due to death $(n=6.3 \%)$, but their data were included in the analyses for the waves preceding their death. The mean levels of psychological distress based on imputed data sets were higher (women: $6.4 \%$ to 8.1\%; men: $16.7 \%$ to $19.2 \%$ ) than the observed mean levels, which is consistent with the fact that respondents lost to follow-up expressed higher mean levels of distress than those who remained in the survey.

\section{Ethics}

This study was approved by the ethics committee of the Institut universitaire en santé mentale de Montréal. Access to the NPHS data was granted by the Social Science and Humanities Council of Canada and by Statistics Canada. Analyses were carried out at the Centre Interuniversitaire Québécois de Statistiques Sociales (CIQSS). Informed consent from participants was obtained by Statstics Canada.

\section{Results}

\section{Descriptive data}

Table 1 displays the means for psychological distress and their confidence intervals by gender, age group and birth cohort. Comparison of these confidence intervals indicates that the mean level of distress is statistically higher in women than in men (for all age groups and birth cohorts), in younger than in older adults, and in more recent than in earliest birth cohorts. In both women and men, the highest mean level of psychological distress is found in the 18-29 age group. The level then decreases steadily until reaching its minimum in the 60-69 age group, again increasing in older groups but without reaching the mean level observed in young adults (20 to 39). The mean level of distress decreases steadily from the most recent birth cohort to the 1930-1939 cohort and increases slightly thereafter.

\section{Growth curve analyses}

Table 2 displays the estimated growth curve coefficients for women. The null model indicates that most (62.1\%) of the variation of the longitudinal distribution of psychological distress is explained by residual intraindividual variation. This residual variation is reduced by $11.6 \%$ with the addition of age variables in Model 2. The estimated coefficient for age in this model indicates that the mean level of psychological distress decreases by .03 for each additional year of age among women. The estimated coefficient for age ${ }^{3}$ is statistically significant, thus confirming the curvilinearity of the age distribution observed in Table 1 and illustrated in Figure 1.

The estimated coefficient for the interaction between age and cohort (Model 4) indicates that the effect of age on the distribution of psychological distress decreases by .007 for each additional birth cohort. The ten-fold decrease in the estimated coefficient for age in Model 5 compared to Model 4 (Model 4: $\beta_{\text {Age }}=-.04$; Model 5: $\beta_{\text {Age }}=-.004$ ) suggests that employment status, marital status and educational level largely account for the effect of age observed in models 2 to 4 . Controlling for these variables also accentuates the curvilinear nature of the age distribution (Model 4: $\beta_{\text {Age }}^{3}=.00001 ;$ Model 5: $\left.\beta_{\text {Age }}^{3}=.00002\right)$, the cohort effect (Model 4: $\beta_{\text {Cohort }}=.19$; Model 5: $\beta_{\text {Cohort }}=.25$ ) and the age by cohort interaction (Model 4: $\beta_{\mathrm{Age} \text { "Cohort }}=-.007$; Model 5: $\left.\beta_{\text {Age } \text { Cohort }}=-.009\right)$.

Table 3 presents the estimated growth curve coefficients for men. As is the case for women, the null model shows that most of the variation in the longitudinal distribution of psychological distress is due to residual intra-individual variation (63.2\%). Adding age variables in Model 2 reduces this residual variation by $9.9 \%$. The growth curve coefficients estimated in models 2 to 4 reveal both differences and similarities when compared with the results for women.

On the one hand, unlike women, the estimated coefficient for age is not statistically significant in men. On the other hand, akin to women, the statistically significant coefficient for age ${ }^{3}$ confirms the curvilinear distribution of psychological distress during adulthood and the estimated coefficient for the interaction between age and cohort indicates that the effect of age on the distribution of psychological distress decreases for each additional birth cohort (Model 4: $\beta_{\text {Age }{ }^{*} \text { Cohort }}=-.009$ ). In effect, the estimated growth curve coefficients in Model 4 are quite similar in women and men (except for the 
Table 1 Mean level of psychological distress by age group and birth cohort

\begin{tabular}{llllll}
\hline Birth cohort & Men $(\mathbf{n}=\mathbf{7 8 7 7})$ & Women $(\mathbf{n}=\mathbf{9 0 6 2})$ & Age group & Men $(\mathbf{n}=\mathbf{7 8 7 7})$ & Women $(\mathbf{n}=\mathbf{9 0 6 2})$ \\
\hline 1980 to 1995 & $3.21(2.96-3.46)^{\mathrm{a}}$ & $4.15(3.85-4.46)$ & 18 to 29 & $3.20(3.05-3.35)$ & $4.01(3.84-4.19)$ \\
1970 to 1979 & $3.16(2.97-3.35)$ & $3.79(3.60-3.98)$ & 30 to 39 & $2.86(2.71-3.01)$ & $3.36(3.22-3.51)$ \\
1960 to 1969 & $2.77(2.63-2.91)$ & $3.22(3.08-3.36)$ & 40 to 49 & $2.59(2.45-2.73)$ & $3.13(2.99-3.26)$ \\
1950 to 1959 & $2.52(2.38-2.67)$ & $3.13(2.99-3.28)$ & 50 to 59 & $2.36(2.22-2.50)$ & $2.96(2.81-3.12)$ \\
1940 to 1949 & $2.28(2.14-2.42)$ & $2.85(2.69-3.01)$ & 60 to 69 & $2.12(1.96-2.29)$ & $2.68(2.51-2.85)$ \\
1930 to 1939 & $2.05(1.87-2.23)$ & $2.71(2.54-2.88)$ & 70 to 79 & $2.10(1.88-2.32)$ & $2.74(2.55-2.93)$ \\
1920 to 1929 & $2.23(2.00-2.47)$ & $2.91(2.68-3.14)$ & 80 and older & $2.48(2.11-2.86)$ & $3.16(2.86-3.47)$ \\
1892 to 1919 & $2.39(1.97-2.81)$ & $3.11(2.77$ to 3.46$)$ & & & \\
\hline
\end{tabular}

${ }^{a}$ Confidence intervals at the 0.95 level adjusted for the survey design effect.

direct effect of age in women). Finally, as is the case in women, controlling for employment status, marital status and educational level (Model 5) increases the estimated coefficients for birth cohort and the interaction between age and cohort in men.

In order to verify the potential impact of multiple imputation on the results, growth curve analyses were repeated using observed data (women $=52897$; men $=$ 42268). Table 4 compares the results of Model 4 based on completed and observed data in women and men. The estimated growth curve coefficients point in the same direction in completed and observed data but they are smaller in completed than in observed data. As a consequence, three coefficients not statistically significant in completed data are significant in observed data (women: age ${ }^{2}$; men: age and birth cohort). The percentage of residual intra-individual variance is slightly larger in completed data (women: 50.5\%; men: 53.1\%) than in observed data (women: 48.2\%; men: 49.1\%).

\section{Post-hoc analyses}

Post-hoc descriptive analyses and exploratory growth curve analyses were conducted to clarify the effects that employment status, marital status and educational level had on the estimated coefficients for age and cohort. See Additional file 1: Table S1A to S6A display the distribution of employment status, marital status and educational level and the mean level of distress for each category of these variables by age group and gender. These data show notable gender differences.

In women, the proportion of not employed is slightly higher in the 18-29 age group (.27) over the course of the NPHS than in the 30-49 age group (.22 to .25 ) and it is highest in seniors (60 and older: .71 to .87 ) (Additional file 1: Table S1A). Non-employment appears to be a risk factor for psychological distress for women aged 18 to 59 but a protective factor for those aged 70 and older (Additional file 1: Table S1A). As is the case for women, the proportion of not employed in men is slightly higher in the 18-29 age group (.24) than in the 30-49 age group (.15 to .22) and it is highest in seniors
(60-69: .54; 70 and older: .80 to .84) (Additional file 1: Table S2A). Non-employment is a risk factor for psychological distress for men aged 18 to 59 but a protective factor for those aged 80 and older (Additional file 1: Table S2A) compared to 70 and older in women.

Being without a spouse is more frequent in the youngest (18-29: .75) and oldest (80 and older: .80) age group than in other adult women (30-79: .33 to .56) (Additional file 1: Table S3A). It is a risk factor for psychological distress in all age groups except in seniors aged 80 and over (Additional file 1: Table S3A). In men, the proportion of individuals without spouse is also highest in the youngest age group (18-29: .84) and lower in other age groups (30 and older: .23 to .43). Unlike women, it is a risk factor for psychological distress in all age groups (Additional file 1: Table S4A).

The proportion of women with a high school diploma or less is higher in the 18-29 age group (.68) than in the 30-59 age group (.56 to .63) and it is highest in seniors (60 and older : .73 to .85) (Additional file 1: Table S5A). A low level of education is a risk factor for psychological distress in all age groups in women (Additional file 1: Table S5A). The proportion of men with a high school diploma or less is higher in the 18-29 age group (.74) and in seniors (70 and older: .75 to .79 ) than in the 30 69 age group (.55 to .66) (Additional file 1: Table S6A). Contrary to women, a low educational level is a risk factor only in young men (18-39).

Findings from exploratory growth curve analyses in women (Table 5) suggest that the substantial decline in the estimated coefficient for age in Model $5(\beta=-.004)$ compared to Model 4 $(\beta=-.04)$ may have been caused by the interactions between age and employment status and between age and marital status that were not taken into account in Model 5. These statistically significant interactions indicate that the effect of age on the distribution of psychological distress is lower in not employed women than in employed, and in single, divorced, separated or widowed women than in those with a spouse. The slight increase in the estimated coefficient for birth cohort age in Model $5(\beta=.19)$ compared to Model 4 
( $\beta=.25)$ appears to be attributable to the direct effect of marital status and to the interaction of employment status and birth cohort. The estimated growth curve coefficient for this interaction indicates that the effect of birth cohort on the distribution of distress is higher in not employed women than in those employed (Table 5).

Findings from exploratory growth curve analyses in men (Table 6) suggest that employment status, marital status and education level, taken in combination rather than individually, account for the two-fold increase in the coefficient for birth cohort in Model $5(\beta=.23)$ compared to Model 4 $(\beta=.12)$. At first glance (Table 6 Model 5f), this increase seems mostly attributable to the interaction of marital status and birth cohort: the effect of birth cohort on the distribution of psychological distress appears to be lower single, divorced, separated and widowed men than in those with a spouse. However, this interaction is no longer statistically significant when employment status and education are taken into account (Model 5h).

\section{Discussion}

\section{Effect of age and birth cohort on the distribution of psychological distress}

The main objective of this study was to examine the distribution of psychological distress during adulthood in women and men. Findings from this study reveal minor gender differences in the distribution of distress among Canadian adults when age and birth cohort are examined

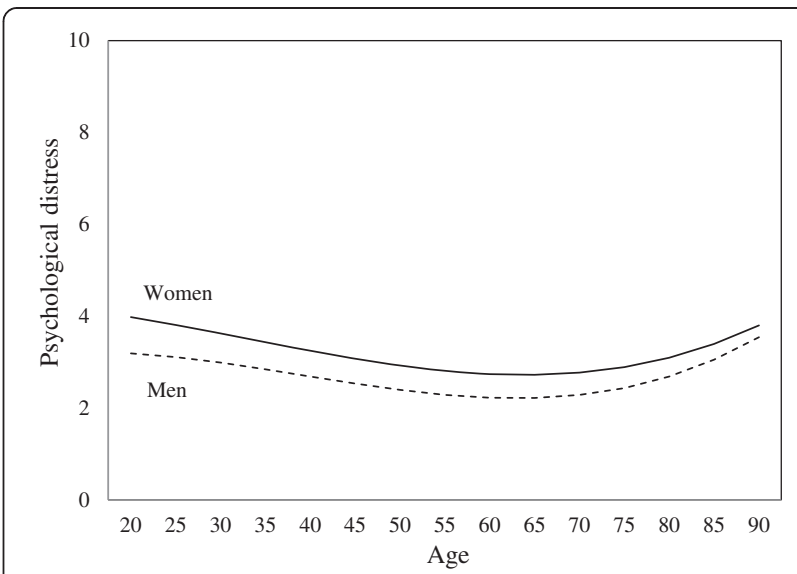

Figure 1 Predicted mean level of psychological distress (Model 2: $\mathrm{Age}+\mathrm{Age}^{2}+\mathrm{Age}^{3}$ ).

jointly using growth curve analyses. In women, the mean level of distress decreases steadily during adulthood beginning at age 18 and evidences a slight curvilinear distribution. In men, the mean level of psychological distress seems to follow a bimodal distribution: it remains relatively stable in the twenties and decreases steadily thereafter before increasing after age 80. However, when the interaction between age and cohort is taken into account, the distribution of psychological distress during adulthood is quite similar in women and men. In addition, the curvilinear or bimodal distribution observed in women and men is hardly noticeable since

Table 2 Estimates of growth curve coefficients - women $(n=9062)$

\begin{tabular}{|c|c|c|c|c|c|}
\hline & Model 1 & Model 2 & Model 3 & Model 4 & Model 5 \\
\hline \multicolumn{6}{|l|}{ Fixed effects } \\
\hline Intercept & $3.22^{* * *}$ & $4.04^{* * *}$ & $4.06^{* * *}$ & $3.93^{* * *}$ & $2.97^{* * *}$ \\
\hline Age & & $-.03^{*}$ & $-.03^{*}$ & $-.04^{* *}$ & -.004 \\
\hline $\mathrm{Age}^{2}$ & & -.0006 & -.0006 & .0002 & -.0008 \\
\hline $\mathrm{Age}^{3}$ & & $.00001^{* *}$ & $.00001^{* *}$ & $.00001^{* *}$ & $.00002^{* * *}$ \\
\hline Cohort & & & -.02 & $.19^{*}$ & $.25^{* *}$ \\
\hline Cohort *Age & & & & $-.007^{* *}$ & $-.009^{* * *}$ \\
\hline Not employed & & & & & $.16^{* *}$ \\
\hline Lower education & & & & & $.21^{* * *}$ \\
\hline Without spouse & & & & & $.54^{* * *}$ \\
\hline \multicolumn{6}{|l|}{ Random effects (variance) } \\
\hline Intercept (between) & 4.51 & 6.96 & 6.95 & 6.99 & 6.71 \\
\hline Slope (between) & & .004 & .004 & .004 & .004 \\
\hline Residuals (within) & 7.39 & 7.09 & 7.09 & 7.09 & 7.08 \\
\hline \multicolumn{6}{|l|}{$I C C^{a}$} \\
\hline Intercept (between) & .379 & .495 & .495 & .496 & .487 \\
\hline Residuals (within) & .621 & .505 & .505 & .504 & .513 \\
\hline
\end{tabular}

$*<.05 ; * *<.01 ; * * *<.001$.

aICC: Intra-class correlation coefficient. 
Table 3 Estimates of growth curve coefficients - men $(n=7877)$

\begin{tabular}{|c|c|c|c|c|c|}
\hline & Model 1 & Model 2 & Model 3 & Model 4 & Model 5 \\
\hline \multicolumn{6}{|l|}{ Fixed effects } \\
\hline Intercept & $2.65^{* * *}$ & $3.21^{* * *}$ & $3.35^{* * *}$ & $3.21^{* * *}$ & $2.29^{* * *}$ \\
\hline Age & & -.007 & -.001 & -.014 & .013 \\
\hline $\mathrm{Age}^{2}$ & & $-.001^{* *}$ & $-.001^{* *}$ & -.0002 & -.0008 \\
\hline $\mathrm{Age}^{3}$ & & $.00002^{* * *}$ & $.00002^{* * *}$ & $.00002^{* * *}$ & $.00002^{* * *}$ \\
\hline Cohort & & & $-.14^{* *}$ & .12 & $.23^{* *}$ \\
\hline Cohort *Age & & & & $-.009^{* * *}$ & $-.010^{* * *}$ \\
\hline Not employed & & & & & $.22^{* *}$ \\
\hline Lower education & & & & & $.17^{* * *}$ \\
\hline Without spouse & & & & & $49^{* * *}$ \\
\hline \multicolumn{6}{|l|}{ Random effects (variance) } \\
\hline Intercept (between) & 3.43 & 4.94 & 4.94 & 4.94 & 4.93 \\
\hline Slope (between) & & .004 & .004 & .004 & .004 \\
\hline Residuals (within) & 5.89 & 5.63 & 5.63 & 5.63 & 5.63 \\
\hline \multicolumn{6}{|l|}{$\mathrm{ICC}^{\mathrm{a}}$} \\
\hline Intercept (between) & .368 & .467 & .467 & .467 & .467 \\
\hline Residuals (within) & .632 & .533 & .533 & .533 & .533 \\
\hline
\end{tabular}

${ }^{*}<.05 ;{ }^{* *}<.01 ;{ }^{* * *}<.001$.

a ICC: Intra-class correlation coefficient.

the growth curve coefficients for quadratic age and cubic age are very small.

Data regarding the shape of the age distribution for psychological distress in adults are scarce and come almost exclusively from cross-sectional surveys (Jorm et al. 2005; Schieman et al. 2001; Turcotte and Schellenberg 2007). The present study was based on a national longitudinal survey for which data were collected every two years between 1994-1995 and 2010-2011 (9 waves). The sample under study covered a broad age range (18 years old and older) and spanned several birth cohorts (1892 to 1995). These methodological features allowed conducting a more in-depth investigation of the distribution of psychological distress during adulthood than has been the case in previous studies.

The cross-sectional studies conducted by Schieman et al. (2001) and Turcotte and Schellenberg (2007) also covered a broad age range and provided evidence bearing on the curvilinear distribution of psychological distress during adulthood. Schieman et al. (2001) targeted

Table 4 Estimates of growth curve by gender (completed vs. observed data)

\begin{tabular}{|c|c|c|c|c|}
\hline & \multicolumn{2}{|l|}{ Women } & \multicolumn{2}{|l|}{ Men } \\
\hline & $\begin{array}{l}\text { Completed data } \\
(\mathrm{n}=69020)^{\mathrm{a}}\end{array}$ & $\begin{array}{l}\text { Observed data } \\
(n=52897)\end{array}$ & $\begin{array}{l}\text { Completed data } \\
(n=58302)\end{array}$ & $\begin{array}{l}\text { Observed data } \\
(n=42268)\end{array}$ \\
\hline \multicolumn{5}{|l|}{ Fixed effects } \\
\hline Intercept & $3.93^{* * *}$ & $3.90^{* * *}$ & $3.21^{* * *}$ & $3.15^{* * *}$ \\
\hline Age & $-.04^{* *}$ & $-.08^{* * *}$ & -.014 & $-.07^{* * *}$ \\
\hline $\mathrm{Age}^{2}$ & .0002 & $.0001^{* * *}$ & -.0002 & .0009 \\
\hline $\mathrm{Age}^{3}$ & $.00001^{* *}$ & $.000003^{* * *}$ & $.00002^{* * *}$ & $.000003^{* * *}$ \\
\hline Cohort & $.19^{*}$ & $.40^{* * *}$ & .12 & $.38^{* * *}$ \\
\hline Cohort *Age & $-.007^{* *}$ & $-.008^{* * *}$ & $-.009^{* * *}$ & $-.009^{* * *}$ \\
\hline \multicolumn{5}{|l|}{$\mathrm{ICC}^{\mathbf{b}}$} \\
\hline Between-person & .495 & .518 & .469 & .509 \\
\hline Within-person & .505 & .482 & .531 & .491 \\
\hline
\end{tabular}

${ }^{*}<.05 ;{ }^{* *}<.01 ;{ }^{* * *}<.001$.

${ }^{\mathrm{a}}$ Number of observations.

bICC: Intra-class correlation coefficient. 
Table 5 Exploratory analyses - estimates of growth curve coefficients - women $(n=9062)$

\begin{tabular}{|c|c|c|c|c|c|c|c|}
\hline & Model 5a & Model 5b & Model 5c & Model 5d & Model 5e & Model $5 f$ & Model $5 \mathrm{~h}$ \\
\hline \multicolumn{8}{|l|}{ Fixed effects } \\
\hline Intercept & $3.86^{* *}$ & $3.84^{* * *}$ & $3.51^{* * *}$ & $3.53^{* *}$ & $3.40^{* * *}$ & $3.13^{* * *}$ & $2.69^{* * *}$ \\
\hline Age & $-.04^{*}$ & $-.03^{*}$ & -.03 & -.02 & -.02 & .01 & .02 \\
\hline $\mathrm{Age}^{2}$ & -.0001 & .0001 & -.0003 & -.0003 & -.0004 & $-.0011^{*}$ & $-.0011^{*}$ \\
\hline $\mathrm{Age}^{3}$ & $.00001^{* * *}$ & $.00001^{* * *}$ & $.00001^{* * *}$ & $.00002^{* * *}$ & $.00002^{* * *}$ & $.00002^{* * *}$ & $.00002^{* * *}$ \\
\hline Cohort & $.21^{*}$ & $20^{*}$ & .16 & .07 & $.25^{* *}$ & $.21^{*}$ & $.25^{* *}$ \\
\hline Cohort *Age & $-.008^{*}$ & $-.012^{* * *}$ & $-.007^{* *}$ & $-.007^{* *}$ & $-.008^{* *}$ & $-.008^{* *}$ & $-.012^{* * *}$ \\
\hline Not employed & $.15^{*}$ & $.23^{*}$ & & & & & .21 \\
\hline Employment *Age & & $-.03^{* * *}$ & & & & & $-.03^{* * *}$ \\
\hline Employment ${ }^{*}$ Cohort & & $.30^{* *}$ & & & & & $.30 * *$ \\
\hline Low education & & & $.24^{* * *}$ & $.22^{* *}$ & & & $20^{* * *}$ \\
\hline Education ${ }^{*}$ Age & & & & -.006 & & & \\
\hline Education *Cohort & & & & .07 & & & \\
\hline Without spouse & & & & & $.55^{* * *}$ & $.83^{* * *}$ & $.83^{* * *}$ \\
\hline Marital status *Age & & & & & & $-.02^{* *}$ & $-.02^{* *}$ \\
\hline Marital status ${ }^{*}$ Cohort & & & & & & .10 & \\
\hline \multicolumn{8}{|l|}{ Random effects (variance) } \\
\hline Intercept (between) & 6.96 & 6.89 & 6.91 & 6.90 & 6.82 & 6.77 & 6.62 \\
\hline Slope (between) & .004 & .004 & .004 & .004 & .004 & .004 & .004 \\
\hline Residuals (within) & 7.09 & 7.09 & 7.09 & 7.09 & 7.08 & 7.07 & 7.07 \\
\hline \multicolumn{8}{|l|}{$I C C^{a}$} \\
\hline Intercept (between) & .495 & .493 & .494 & .493 & .491 & .489 & .495 \\
\hline Residuals (within) & .505 & .507 & .506 & .507 & .509 & .511 & .505 \\
\hline
\end{tabular}

${ }^{*}<.05 ;{ }^{* *}<.01 ;{ }^{* * *}<.001$.

aCC: Intra-class correlation coefficient.

individuals aged 18-89 and grouped them into ten-year age categories. They found that the mean level of distress was higher among young adults (18-29 years), reached its lowest level in the 60-69 group, and then increased among those aged 70 and older. The study by Turcotte and Schellenberg (2007) compared the health of seniors and younger adults. It grouped respondents into four age ranges: $25-54,55-64,65-74$ and 75 and older. Turcotte and Schellenberg (2007) observed a decline in the mean level of distress that bottomed out with the 65-74 age group, then increased among respondents aged 75 and older. Findings from our study generally agree with those of Schieman et al. (2001) and Turcotte and Schellenberg (2007). But they also indicate that the distribution of psychological distress may be more bimodal than curvilinear among adult males.

Findings from our study also partly agree with the gender differences highlighted by Jorm et al. (2005). That study examined the age distribution for psychological distress in Australians aged 20-24, 40-44 and 60-64. It found that, among men, the mean level of distress was similar in the younger age groups (20-24 and 40-44) and lower in the oldest group (60-64). By contrast, distress levels among women diminished steadily between 20 and 64. In the present study, the mean level of distress in Canadian women was found to decrease steadily during adulthood and to reach its lowest point in the 60-69 age group, but among Canadian men the decrease was preceded by a plateau of high distress in the 18-29 age group. The age range (20-64) of the sample investigated by Jorm et al. (2005) was not large enough to reveal a putative increase in psychological distress in seniors as observed in the present study.

Finally, findings from our study concur to some extent with those of Sacker and Wiggins (2002) based on a small age range (23-42) and two birth cohorts (1958 and 1970). Sacker and Wiggins (2002) found that the rate of psychological distress was higher in the most recent cohort than in the earliest cohort. A similar cohort effect on the distribution of psychological distress was noticed in Canadian adults when the interaction between age and cohort was taken into account.

Several authors have hypothesized that the age distribution observed for psychological distress may be confounded 
Table 6 Exploratory analyses - estimates of growth curve coefficients - men $(n=7877)$

\begin{tabular}{|c|c|c|c|c|c|c|c|}
\hline & Model 5a & Model 5b & Model 5c & Model 5d & Model 5e & Model $5 f$ & Model $5 \mathrm{~h}$ \\
\hline \multicolumn{8}{|l|}{ Fixed effects } \\
\hline Intercept & $3.10^{* * *}$ & $3.05^{* * *}$ & $2.84^{* * *}$ & $2.74^{* * *}$ & $2.69^{* * *}$ & $2.59^{* * *}$ & $2.12^{* * *}$ \\
\hline Age & -.010 & -.006 & -.006 & -.003 & .002 & -.001 & .020 \\
\hline $\mathrm{Age}^{2}$ & -.0003 & -.0003 & -.0004 & -.0005 & -.0005 & -.0003 & $-.0010^{*}$ \\
\hline $\mathrm{Age}^{3}$ & $.00002^{* * *}$ & $.00002^{* * *}$ & $.00002^{* * *}$ & $.00002^{* * *}$ & $.00002^{* * *}$ & $.00002^{* * *}$ & $.00002^{* * *}$ \\
\hline Cohort & .16 & .17 & .12 & .15 & $.19^{*}$ & $.32 * * *$ & $.27^{* *}$ \\
\hline Cohort *Age & $-.011^{* * *}$ & $-.012^{* * *}$ & $-.002^{* * *}$ & $-.009^{* * *}$ & $-.010^{* * *}$ & $-.010^{* * *}$ & $-.012^{* * *}$ \\
\hline Not employed & $24 * * *$ & $.41^{* *}$ & & & & & $.38^{* *}$ \\
\hline Employment ${ }^{*}$ Age & & $-.02^{*}$ & & & & & -.01 \\
\hline Employment ${ }^{*}$ Cohort & & .17 & & & & & \\
\hline Low education & & & $.19^{* * *}$ & $.25^{* *}$ & & & $.16^{* * *}$ \\
\hline Education *Age & & & & -.0003 & & & \\
\hline Education ${ }^{*}$ Cohort & & & & -.024 & & & \\
\hline Without spouse & & & & & $.50^{* * *}$ & $.62^{* * *}$ & $.63^{* * *}$ \\
\hline Marital status *Age & & & & & & .02 & \\
\hline Marital status ${ }^{*}$ Cohort & & & & & & $-.20^{*}$ & -.06 \\
\hline \multicolumn{8}{|l|}{ Random effects (variance) } \\
\hline Intercept (between) & 4.96 & 4.93 & 4.95 & 4.95 & 4.93 & 4.93 & 4.91 \\
\hline Slope (between) & .004 & .004 & .004 & .004 & .004 & .004 & .004 \\
\hline Residuals (within) & 5.62 & 5.62 & 5.62 & 5.62 & 5.62 & 5.62 & 5.61 \\
\hline \multicolumn{8}{|l|}{$\mathrm{ICC}^{\mathrm{a}}$} \\
\hline Intercept (between) & .469 & .467 & .468 & .468 & .467 & .467 & .467 \\
\hline Residuals (within) & .531 & .533 & .532 & .532 & .533 & .533 & .533 \\
\hline
\end{tabular}

${ }^{*}<.05 ;{ }^{* *}<.01 ;{ }^{* * *}<.001$.

aCC: Intra-class correlation coefficient.

by a cohort effect (Brault et al. 2011; Chiao et al. 2009; Kasen et al. 2003; Jorm 2000; Lewinsohn et al. 1993; Mirowsky and Kim 2007; Roberts et al. 1991; Sacker and Wiggins 2002; Yang 2007). Thus, for instance, young adults might express a higher mean level of distress than older adults not only because they are exposed to more risk factors or because they are more vulnerable to those risk factors, but, at least partly, because they were born at a time when these factors were more prevalent or potentially more harmful. In the present study, the effect of age on the distribution of psychological distress was not confounded by the effect of cohort but it was moderated by the latter.

\section{Effect of covariates on the age distribution of psychological distress}

Findings from this study show that controlling for employment status, marital status and educational level produce a ten-fold decrease in the effect of age on the distribution of psychological distress in women and a two-fold increase in the effect that birth cohort has on the distribution of distress in men. Exploratory growth curve analyses suggest that, in women, the effect of age is lower among the not employed and among individuals without spouses and the effect of cohort is higher among the not employed. Among men, the effect of age is also lower among the not employed; whereas the effect of cohort is lower in individuals without spouses. However, the interactions between age and employment status and between birth cohort and marital status are no longer statistically significant in men when employment status, marital status and education are taken into account together.

Several studies have shown that non-employment (Marchand et al. 2012; Matthews et al. 2001; Talala et al. 2007; Walters et al. 2002), being without a spouse (Marchand et al. 2012; Matthews et al. 2001; Talala et al. 2007) and low educational level (Mandemakers and Monden 2010; Talala et al. 2007; Walters et al. 2002) are associated with psychological distress. To our knowledge, no studies have compared the effect of these variables on psychological distress in different age groups. Findings from this study indicate that nonemployment may be a risk factor for women and men 
in the 18-59 age group but not in older adults. In contrast, low educational level tends to remain a risk factor in all adulthood in women whereas, in men, its deleterious effect is confined to the 18-39 age group. Additional research is needed to better understand the complex interplay between psychological distress and the contextual variation in non-employment, lack of a spouse and low educational level during adulthood in women and in men.

\section{Limitations}

The main limitation of this study is the small number of cohorts in each age group, especially at the extremities of the age distribution. The youngest (18-29) and the oldest (80 and older) age group each cover three birth cohorts whereas the other age groups each cover four birth cohorts. A second limitation is that the interactions examined in exploratory growth curve analyses (i.e., age and birth cohort by employment status, marital status and education) were not included in the imputation model. Rubin (1987) and others recommend that all variables used in subsequent analyses be part of the imputation model. Given that there are nine waves of data collection in the NPHS and that multiple imputation was performed on a wide-format file, these interactions required the creation of 54 variables. The addition of these variables to an imputation model that already contains more than 100 variables could not be managed by the ICE program. A third limitation is that employment status, marital status and education were each defined by a single variable. In consequence, it cannot be determined which dimensions of these variables is responsible for the age, cohort and gender differences observed in the exploratory growth curve analyses. Finally, as in other longitudinal studies that span a long period, the birth cohort observed in this study cannot be distinguished from a putative period effect.

\section{Conclusion}

Age and gender are useful risk markers because they shift the focus of epidemiological research and public health programs towards risk and protective factors that are more prevalent in certain age groups and in women or men (World Health Organization 2005). Findings from our study indicate that the risk of psychological distress, which is higher for younger adults than for older adults and for women than for men in all age groups, may be related to the changing features of employment status, marital status and educational level during adulthood. Additional research is needed to identify which of these features have the highest prevalence in younger adults, women and men.

\section{Additional file}

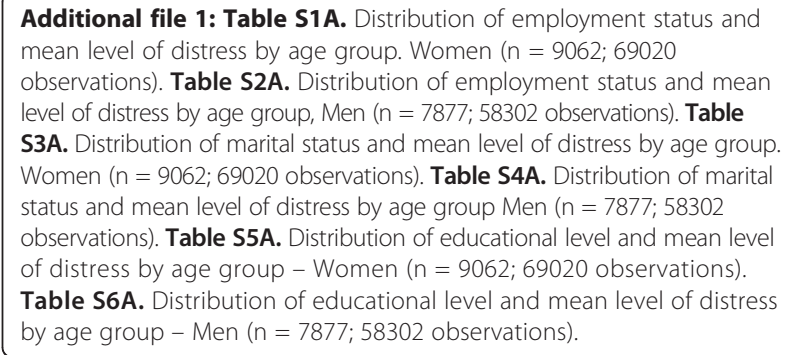

Competing interests

The authors declare that they have no competing interests.

\section{Authors' contributions}

$A D$ designed the study, supervised the review of the literature, performed statistical analyses, assumed leadership for the interpretation of findings and wrote the manuscript. AM participated in statistical analyses and in the interpretation of findings and reviewed the manuscript. CF conducted the review of the literature and wrote a first draft of the background section. All authors read and approved the final manuscript.

\section{Acknowledgements}

This study was supported by the Fonds de la recherche en santé du Québec (ref. \#14389) and was carried out while two of the authors (AD and AM) were supported by researcher' awards from the Fonds de la recherche en santé du Québec.

\section{Author details}

${ }^{1}$ Centre de recherche - Institut universitaire en santé mentale de Montréal, 7331 rue Hochelaga, H1N 3X6 Montreal, Canada. ²Département de psychiatrie, Université de Montréal, Montréal, Canada. ${ }^{3}$ Département de Médecine Sociale et Préventive, Université de Montréal, Montréal, Canada. ${ }^{4}$ École de Relations Industrielles, Université de Montréal, C.P. 6128, succursale Centre-ville, H3C 3 J7 Montréal, Canada. Institut de Recherche en Santé Publique, Université de Montréal, Montréal, Canada. ${ }^{6}$ Département de Médecine, Université de Montréal, Montréal, Canada.

Received: 11 February 2014 Accepted: 22 July 2014

Published: 9 August 2014

\section{References}

Baillie, AJ. (2005). Predictive gender and education bias in Kessler's psychological distress scale (K10). Social Psychiatry and Psychiatric Epidemiology, 40, 743-748.

Benzeval, M, \& Judge, K. (2001). Income and health: the time dimension. Social Science and Medicine, 52, 1371-1390

Brault, MC, Bart, M, \& Bracke, P. (2011). Depressive symptoms in the Belgian population: disentangling age and cohort effects. Social Psychiatry and Psychiatric Epidemiology, 47, 903-915.

Caron, J, \& Liu, A. (2011). Factors associated with psychological distress in the Canadian population: a comparison of low-income and non low-income sub-groups. Community Mental Health Journal, 47, 318-330.

Catlin, G, \& Will, P. (1992). The national population health survey: highlights of initial developments. Health Reports (Statistics Canada), 4, 313-319.

Chiao, C, Weng, LJ, \& Botticello, A. (2009). Do older adults become more depressed with age in Taiwan? The role of social position and birth cohort. Journal of Epidemiology \& Community Health, 63, 625-632.

Chittleborough, CR, Winefield, H, Gill, TK, Koster, C, \& Taylor, AW. (2011). Age differences in associations between psychological distress and chronic conditions. International Journal of Public Health, 56, 71-80.

Collins, LM, Schafer, JL, \& Kam, C-M. (2001). A comparison of inclusive and restrictive strategies in modern missing data procedures. Psychological Methods, 6, 330-351.

Delorme, A, Breton, M, Bouchard, S, Deschênes, L, Hince, C, \& Rhéaume, J. (2005). Plan d'action en Santé Mentale 2005-2010. La Force des Liens. In Direction. 
de la Santé Mentale. Québec: Ministère de la Santé et des Services sociaux Gouvernement du Québec.

Drapeau, A, Beaulieu-Prévost, D, Marchand, A, Boyer, R, Préville, M, \& Kairouz, S. (2010). A life-course and time perspective on the construct validity of psychological distress in women and men. Measurement invariance of the K6 across gender. BMC Medical Research Methodology, 10(68) . http://www.biomedcentral.com/1471-2288/10/68

Drapeau, A, Marchand, A, \& Beaulieu-Prévost, D. (2011). Epidemiology of Psychological Distress. In Luciano L'abate (Ed.), Mental Illness. Understanding, Prediction and Control (pp. 105-134). Croatia: InTech Open Access Publisher.

Enders, CK. (2010). Applied Missing Data Analysis. New York: Guilford Press.

Furukawa, TA, Kessler, RC, Slade, T, \& Andrews, G. (2003). The performance of the $\mathrm{K} 6$ and $\mathrm{K} 10$ screening scales for psychological distress in the Australian National Survey of Mental Health and Well-Being. Psychological Medicine, 33, 357-362

Gispert, R, Rajmil, L, Schiaffino, A, \& Herdman, M. (2003). Sociodemographic and health-related correlates of psychiatric distress in a general population. Social Psychiatry and Psychiatric Epidemiology, 38, 677-683.

Graham, JW, Olchowski, AE, \& Gilreath, TD. (2007). How many imputations are really needed? Some practical clarifications of multiple imputation theory. Prevention Research, 8, 206-213.

Gudmundsdottir, G, \& Vilhjalmsson, R. (2010). Group differences in outpatient help-seeking for psychological distress: results from a national prospective study of Icelanders. Scandinavian Journal of Public Health, 38, 160-167.

Herman, H, Saxena, S, \& Moodie, R. (2005). Promoting Mental Health: Concepts, Emerging Evidence, Practice. In World Health Organization (Ed.), Departmen of Mental Health and Substance Abuse in collaboration with the Victorian Health Promotion Foundation and the University of Melbourne. Genève (Suisse): World Health Organization.

Jorm, AF. (2000). Does old age reduce the risk of anxiety and depression? A review of epidemiological studies across the adult life span. Psychological Medicine, 30, 11-22.

Jorm, AF, Windsor, TD, Dear, KBG, Anstey, KJ, Christensen, H, \& Rodgers, B. (2005). Age group differences in psychological distress: the role of psychosocial risk factors that vary with age. Psychlogical Medicine, 35, 1253-1263.

Kasen, S, Cohen, P, Chen, H, \& Castille, D. (2003). Depression in adult women: age changes and cohort effects. American Journal of Public Health, 93. 2061-2066.

Kessler, RC, Foster, C, Webster, S, \& House, JS. (1992). The relationship between age and depressive symptoms in two national surveys. Psychology and Aging, 7, 119-126.

Kessler, RC, Andrews, G, Colpe, LJ, Hiripi, E, Mroczek, D, Normand, S-LT, Walters, EE, \& Zaslavsky, AM. (2002). Short screening scales to monitor population prevalences and trends in non-specific psychological distress. Psychological Medicine, 32, 959-976.

Kessler, RC, Barker, PR, Colpe, L, Epstein, JF, Gfroerer, JC, Hipipi, E, Howes, MJ, Normand, SLT, Manderschied, RW, Walters, EE, \& Zaslavsky, AM. (2003). Screening for serious mental illness in the general population. Archives of General Psychiatry, 60, 184-189.

Knapp, M, McDaid, D, Mossialos, E, \& Thornicroft, G. (2007). Mental Health Policy and Practice Across Europe. The Future Direction of Mental Health Care. United Kingdom: European Observatory On Health Systems And Policies Series.

Koopmans, GT, Donker, MCH, \& Rutten, FHH. (2005). Common mental disorders and use of general health services: a review of the literature on population-based studies. Acta Psychiatrica Scandinavica, 111, 341-350.

Langlois, KA, \& Garner, R. (2013). Trajectoires de la détresse psychologique au Canada chez les adultes ayant été exposés à une dépendance parentale dans leur enfance. Rapports sur la santé - Statistique Canda, 24, 15-23.

Levecque, K, Lodewyckx, I, \& Bracke, P. (2009). Psychological distress, depression and generalised anxiety in Turkish and Moroccan immigrants in Belgium: a general population study. Social Psychiatry and Psychiatric Epidemiology, 44, 188-197.

Lewinsohn, PM, Rohde, P, Seeley, JR, \& Fischer, SA. (1993). Age-cohort changes in the lifetime occurence of depression and other mental disorders. Journal of Abnormal Psychology, 102, 110-120.

Lin, M-T, Burgess, JF, \& Carey, K. (2012). The association between serious psychological distress and emergency department utilization among young adults in the USA. Social Psychiatry and Psychiatric Epidemiology, 47, 939-947.
Mandemakers, JJ, \& Monden, CW. (2010). Does education buffer the impact of disability on psychological distress? Social Science and Medicine, 71, 288-297.

Marchand, A, Drapeau, A, \& Beaulieu-Prévost, D. (2012). Psychological distress in Canada: the role of employment and reasons for non-employment. International Journal of Social Psychiatry, 58, 596-604

Matthews, S, Power, C, \& Stansfeld, SA. (2001). Psychological distress and work and home roles: a focus on socio-economic differences in distress. Psychological Medicine, 31, 725-736.

Mirowsky, M, \& Kim, J. (2007). Graphing age trajectories. Vector graphs, synthetic and virtual cohort projections, and cross-sectional profiles of depression. Sociological Methods \& Research, 35, 497-541.

Mirowsky, J, \& Ross, CE. (2002). Measurement for a social science. Journal of Health and Social Behavior, 43, 152-170.

Organisation mondiale de la santé. (2006). Classification Statistique Internationale des Maladies et Problèmes de Santé Connexes - Dixième Révision. Genève (Suisse): Organisation mondiale de la santé.

Phillips, MR. (2009). Is distress a symptom of mental disorders, a marker of impairment, both or neither? World Psychiatry, 8, 91-92.

Phongsavan, P, Chey, T, Bauman, A, Brooks, R, \& Silove, D. (2006). Social capital, socio-economic status and psychological distress among Australian adults. Social Science and Medicine, 63, 2546-2561.

Rabe-Hesketh, S, \& Skrondal, A. (2012). Multilevel and Longitudinal Modeling Using Stata. Volume 1: Continuous Responses (3rd ed.). Texas (USA): Stata Press.

Roberts, RE, Lee, ES, \& Roberts, CR. (1991). Changes in prevalence of depressive symptoms in Alameda county. Age, period, and cohort trends. Journal of Aging and Health, 3, 66-86.

Royston, P. (2007). Multiple imputation of missing values: further update of ICE, with an emphasis on interval censoring. Stata Journal, 7, 445-464.

Royston, P, \& White, IR. (2011). Multiple imputation by chained equations (MICE): implementation in stata. Journal of Statistical Software, 45, 1-20.

Rubin, DB. (1987). Multiple Imputation for Nonresponse in Surveys. New-York: John Wiley \& Sons Inc

Rubin, DB. (1996). Multiple imputation after 18+ years. Journal of the American Statistical Association, 91, 473-489.

Sacker, A, \& Wiggins, RD. (2002). Age-period-effect on inequalities in psychological distress, 1981-2000. Psychological Medicine, 32, 977-990.

Sakurai, K, Kawakami, N, Yamaoka, K, Ishikawa, H, \& Hashimoto, H. (2010). The impact of subjective and objective social status on psychological distress among men and women in Japan. Social Science and Medicine, 70, 1832-1829.

Schafer, JL, \& Graham, JW. (2002). Missing data: Our view of the state of the art. Psychological Methods, 7, 147-177.

Schieman, S, Van Gundy, K, \& Taylor, J. (2001). Status, role, and resource explanations for age patterns in psychological distress. Journal of Health and Social Behavior, 42, 80-96.

Statistique Canada. (2013). Tableau 051-0042 - Estimations de la population selon l'état matrimonial ou l'état matrimonial légal, l'âge et le sexe au $1^{\text {er }}$ juillet 2011. CANSIM. http://www5.statcan.gc.ca/cansim/home-accueil?lang=fr.

Statistique Canada. (2011). Tableau 282-0209 - Enquête sur la population active (EPA), estimations selon le diplôme scolaire, le sexe et le groupe d'âge, annuel (personnes sauf indication contraire). CANSIM. http://www5.statcan.gc. $\mathrm{ca} /$ cansim/home-accueil?lang=fr

Statistique Canada. (2012). Tableau 282-0003 - Enquête sur la population active (EPA), estimations selon le niveau de scolarité atteint, le sexe et le groupe d'âge, non désaisonnalisées. CANSIM. http://www5.statcan.gc.ca/cansim/ home-accueil?lang=fr.

Susser, E, Schwartz, S, Morabia, A, \& Bromet, EJ. (2006). Psychiatric Epidemiology: Searching for the Causes of Mental Disorders (Oxford Psychiatry Series). Oxford: Oxford University Press.

Svensson, E, Nyagard, JF, Sorensen, T, \& Sandanger, I. (2009). Changes in formal help seeking for psychological distress: the Oslof study. Nordic Journal of Psychiatry, 63, 260-266.

Talala, K, Huurre, T, Aro, H, Martelin, T, \& Prattala, R. (2007). Socio-demographic differences in self-reported psychological distress among 25- to 64-year-old Finns. Social Indicators Research, 86, 323-335.

Tambay, JL, \& Catlin, G. (1995). Sample design of the National population health survey. Health Reports (Statistics Canada), 7, 1-11.

Turcotte, M, \& Schellenberg, G. (2007). A Portrait of Seniors in Canada. In Social and Aboriginal Statistics Division. Ottawa: Statistics Canada.

Walters, V, McDonough, P, \& Strohschein, L. (2002). The influence of work, household structure, and social, personal and material resources on gender 
differences in health: an analysis of the 1994 Canadian National Population Health Survey. Social Science and Medicine, 54, 677-692.

World Health Organization. (2005). Promoting Mental Health. Concepts. In SSH Herrman \& R Moodie (Eds.), Emerging Evidence. Practice. Geneva

(Suisse): World Health Organization - Department of Mental Health and Substance Abuse.

Yang, Y. (2007). Is old age depressing? Growth trajectories and cohort variations in late-life depression. Journal of Health and Social Behavior, $48,16-32$.

doi:10.1186/s40359-014-0025-4

Cite this article as: Drapeau et al: Gender differences in the age-cohort distribution of psychological distress in Canadian adults: findings from a national longitudinal survey. BMC Psychology 2014 2:25.

\section{Submit your next manuscript to BioMed Central and take full advantage of:}

- Convenient online submission

- Thorough peer review

- No space constraints or color figure charges

- Immediate publication on acceptance

- Inclusion in PubMed, CAS, Scopus and Google Scholar

- Research which is freely available for redistribution 